\title{
Process automatization of creating aerofoil shape in AutoCAD software
}

\author{
Automatyzacja definiowania kształtu profili lotniczych \\ w programie AutoCAD
}

\section{JACEK WARCHULSKI \\ MARCIN WARCHULSKI*}

DOI: https://doi.org/10.17814/mechanik.2017.7.88

\begin{abstract}
Possibilities of using of CAx systems to automation process of graphical tasks are presented. Possibility of using AutoLISP language with VisualLISP environment to create aerofoil shape in CAx system are analysed.
\end{abstract}

KEYWORDS: programming, AutoLISP, Visual LISP, AutoCAD, aerofoil

AutoCAD has many users and takes up a significant place in graphical design. One can program data manipulation tasks, automate graphical tasks, and perform a drawing and share information about it with other applications.

Writing a program to accomplish a specific task usually requires a lot of work, but later you can use the application repeatedly [3]. Creating AutoCAD image rendering automation code in Windows is possible with built-in development tools (e.g. Visual LISP programming environment based on AutoLISP) $[1,2,5,6]$.

\section{Stroke of the carrier}

Traditionally, aerial profiles are drawn in the $X Y$ plane Fig. 1 explains the basic concepts used in the description of the geometry of the airfoil [7].

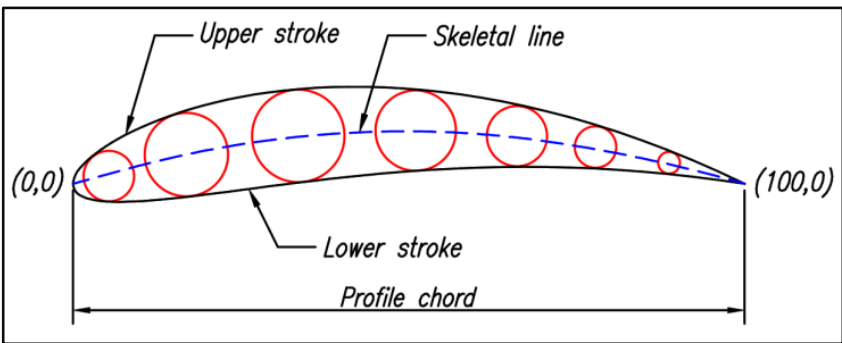

Fig. 1. Geometry of the aviation profile

On the left side, at the point $(0,0)$ there is always nose profile, the shape of which the leading edge of the airfoil. The nose is usually rounded (sometimes the radius of this round is given). The profile is terminated at a point with coordinates $(100,0)$. The profile line is often divided into two parts: the outline of the upper and lower contour. Strokes combine on the edge of the profile. Straight line segment joining the nose of the trailing edge is called a chord. The second characteristic line is the line of airfoil core. Points of the lines are equidistant from the upper and lower edges of the profile. You can imagine it as a

\footnotetext{
* Mjr dr inż. Jacek Warchulski (jacek.warchulski@wat.edu.pl), mjr dr inż. Marcin Warchulski (marcin.warchulski@wat.edu.pl) Wydział Mechatroniki i Lotnictwa Wojskowej Akademii Technicznej
}

line passing through the centers of circles inscribed in the outline of the profile. For the airfoil is defined as parameters such as the maximum thickness of the point of maximum deflection of the frame.

\section{Generator of the aviation profile shape}

To build an airplane profile model, it is necessary to define individual points of the airfoil profile. In this process, you can use Internet generators airfoil, e.g. profile of the "four-digit family" NACA [8, 9]. Generator airfoil to save the coordinates of the nodal points of the profile in the form of text files.

NACA four-digit number profile contains a description of its key geometric parameters [7]:

- first digit: highest skew deflection (the maximum deflection value expressed as a percentage)

- second digit: the distance with the largest skeletal deflection of the profile divided by 10 (e.g. "2" means that the maximum deflection of the skeleton is $20 \%$ from the leading edge),

- third and fourth digits: profile thickness (expressed in percent).

For example, the "NACA 8516" profile symbol indicates a profile of $16 \%$ and a maximum skeletal defect of $8 \%$ at a distance of $50 \%$ of the chord length.

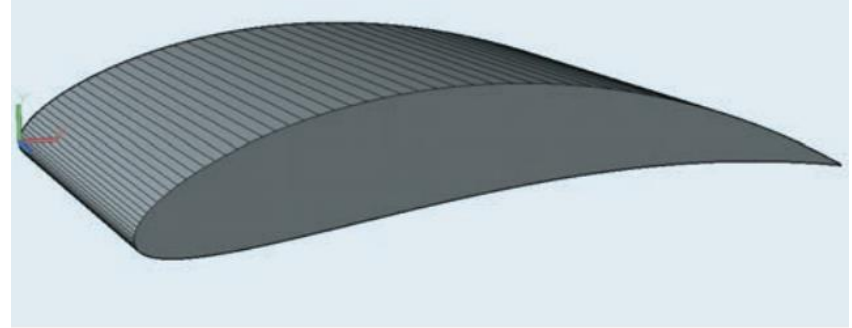

Fig. 2. Profile model "NACA 8516" defined in AutoCAD

Example of the introduction automation of the aviation profile

The AutoLISP programming language and the AutoCAD Visual LISP environment were used to develop a new Profile command, allowing the AutoCAD model to apply a NACA profile stroke whose coordinates are in a ${ }^{*}$.txt file. The profile code for the profile.Isp is shown in fig. 3. 


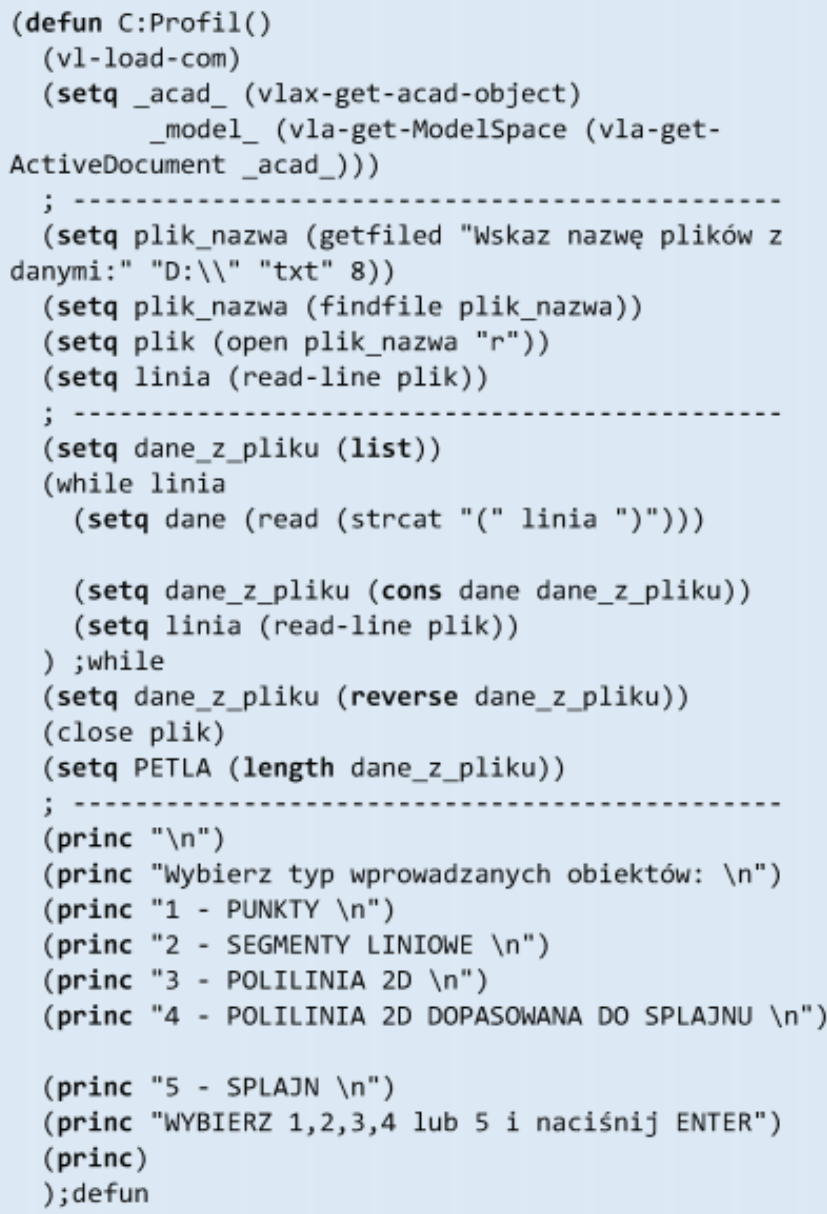

Fig. 3. AutoLISP Profile.Isp master code [4]

The Profile.Isp works as follows:

- a new "AutoCAD - Profile" command is created that does not have any input parameters,

- vl-load-com allows you to call features that allow object-oriented programming; the _acad_global variable is assigned to the AutoCAD document, while model is assigned the active drawing model space,

- using getfiled and findfile allows you to specify a data file and define the path to that file,

- using the open, read-line, and strcat functions allows you to open the file in read-only mode, read individual data lines, join them to a list, and write to a data table,

- since the cons function adds items to the beginning of the list, it also reverses the data in the file_file by using the reverse function,

then the user can select the type of input objects constituting the airfoil (point, line segment, polyline, polyline fit spline, spline).

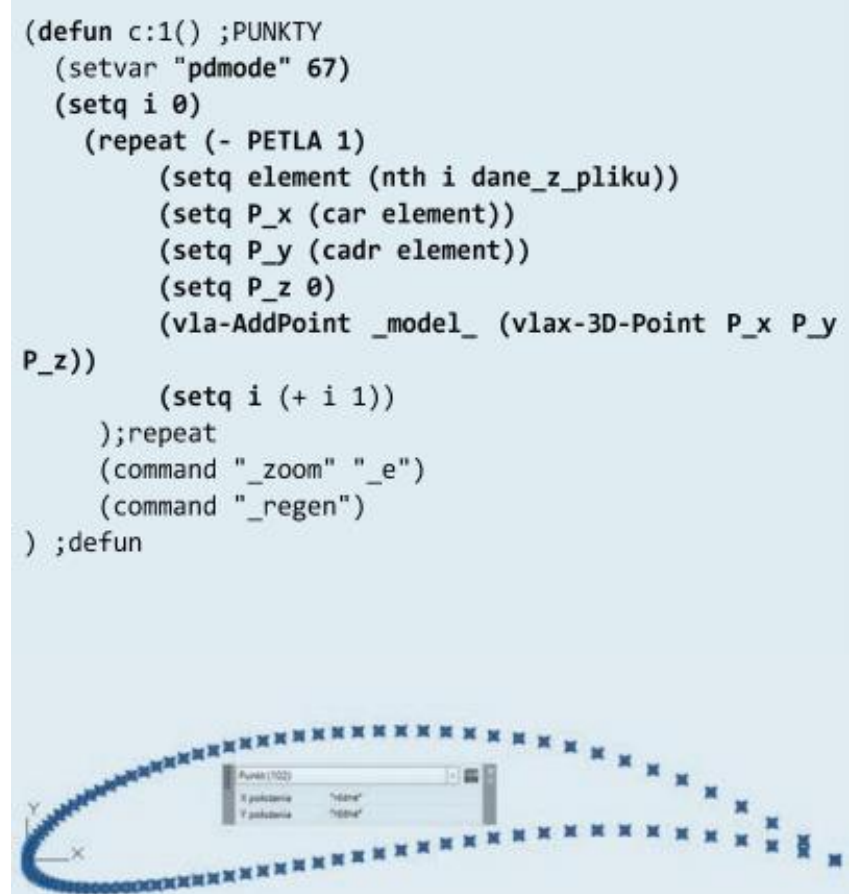

Fig. 4. Code of the subroutine introducing the nodes of the aviation profile

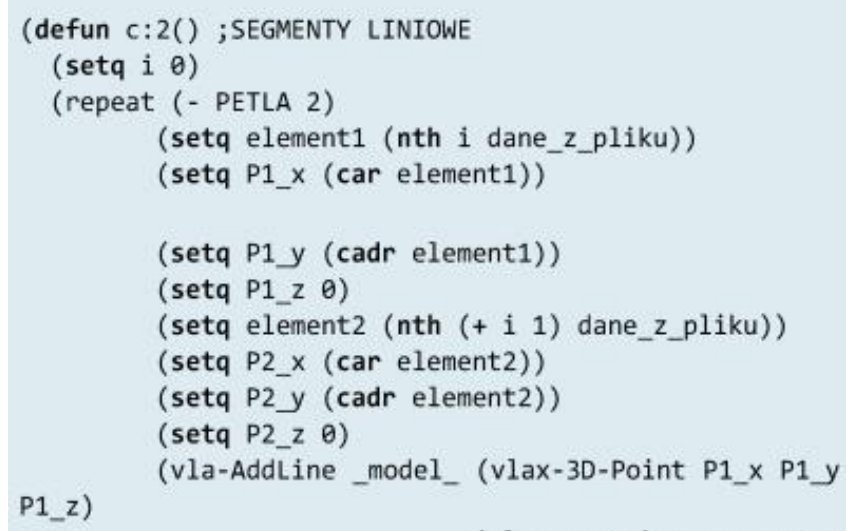

P2_z))

(vlax-3D-Point P2_x P2 y

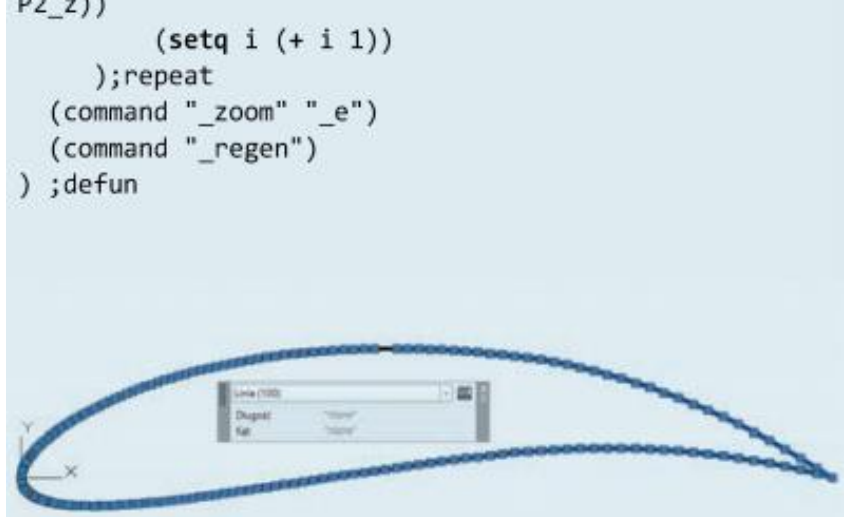

Fig. 5. Code of the subroutine introducing the linear segments of the aviation profile 


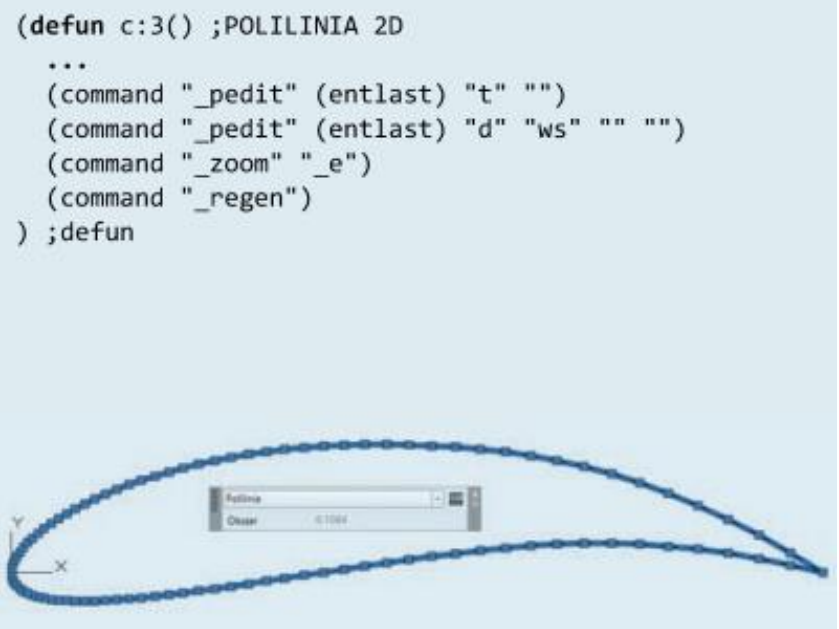

Fig. 6. Subprogram code introducing the aviation profile as a polyline type object
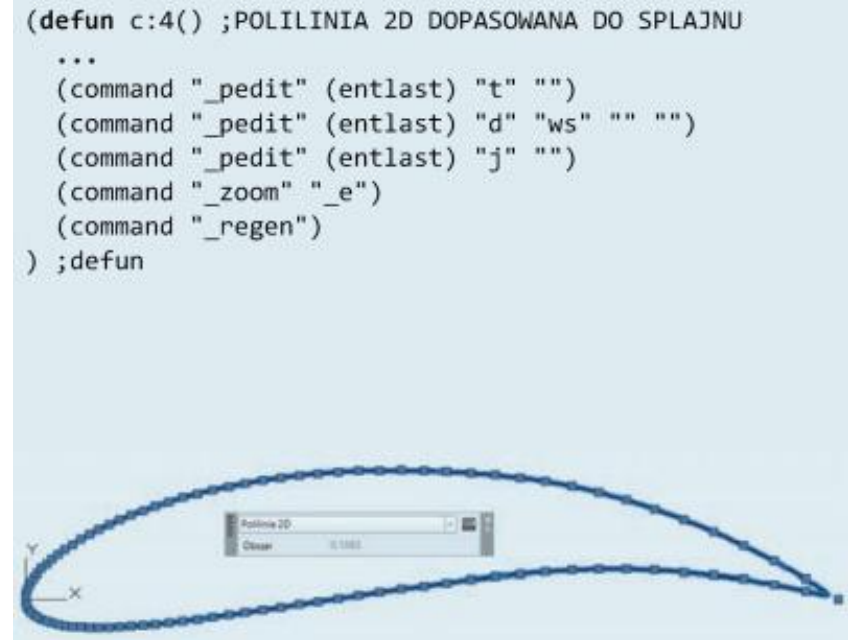

Fig. 7. Subprogram code introducing the aviation profile as a polylines matched to the spline

Selecting the option "1" causes:

- defining the graphical symbol responsible for displaying points (using the pdmode function)

- introduction of point-to-point objects (using the vlaAddPoint command and loop repeat along with nth to select items from the data list).

By selecting the "2" option, the aviation profile will be introduced using linear segments (using the vla-AddLine command).

For subroutines that define another type of airfoil object (polyline, polyline, spline, polyline) (see figs. 6-8), the code common to these programs is omitted (it is identical to the line segment entry code). In this case, you use methods to change an object to polyline, join segments to polyline, change polylines to polyline to fit spline, or spline objects.

\section{Conclusions}

An analysis of the use of newly created AutoLISP command can be used to introduce an aviation profile in the AutoCAD model space. Developing such a program is practical in case one need to create a profile 3D model. The program also allows to enter any shape, the coordinates of nodes of which are defined in the text file.

\section{REFERENCES}

1. Czyżycki W., Lisowski E. „Automatyzacja zadań grafiki za pomoca Delphi". Helion, 2002.

2. Dudek M. ,,AutoLISP. Praktyczny kurs”. Helion, 1997.

3. Warchulski J., Warchulski M. „Przykłady automatyzacji zadan grafiki w programie AutoCAD”. XIV Międzynarodowa Szkoła

Komputerowego Wspomagania Projektowania, Wytwarzania $i$

Eksploatacji. Jurata, 10-14 maja 2010 r., materiały

konferencyjne, pp. 515-522.

4. Warchulski J., Warchulski M. „Program «Profil.lsp»”. Warszawa:

Wojskowa Akademia Techniczna, 2017.

5. https://kojacek.wordpress.com.

6. http://forum.cad.pl/autocad.html

7. http://polskikursblendera.pl/ksiazka/EPUB/text/section-8-3.xhtml.

8. http://www.ppart.de/programming/java/profiles/NACA4.html.

9. http://airfoiltools.com/airfoil/naca4digit. 